\title{
The Impact of Media/Technology on Rural and Urban Children to be Bilingual/ Multilingual
}

\author{
Md. Sozib Hosen \\ Department of English, Khwaja Yunus Ali University, Sirajganj, Bangladesh. \\ sozib.iu.92@gmail.com \\ https://orcid.org/0000-0002-6383-047X \\ Mst. Tanna Khatun \\ Department of English, Khwaja Yunus Ali University, Sirajganj, Bangladesh. \\ tanna.eng.iu@gmail.com
}

DOI: http://doi.org/ 10.36892/ijlls.v3i4.731

\begin{tabular}{ll} 
Received: & Abstract \\
20/09/2021 & This article will focus on the comparative study of the influence of media and \\
\hline Accepted: & technology on rural and urban children to be bilingual and multilingual. The \\
14/11/2021 & study will also shed light on the importance of bilingualism and \\
& multilingualism. TV and YouTube are taken into account as tools of media and \\
& technology for implicit language learning. Children of 8 -12 years are \\
\hline Keywords: & considered as samples of language learners. Data have been collected from a \\
Media and & primary source through a questionnaire and interviews. The result of the \\
Technology, & research shows that there is a significant impact of watching different kinds of \\
Television/YouTube,, & TV/YouTube programs (cartoons, movies, serials, reality shows) which are \\
Bilingual, & presented in foreign languages on children to be bilingual and multilingual \\
Multilingual, & though the results of the rural and urban area are significantly different. In the \\
Children & study, the researchers have found that children living in municipal area are \\
& more bilingual and multilingual compared to children living in rustic area.
\end{tabular}

\section{INTRODUCTION}

In the age of science and technology, it is not always possible to keep children outside the touch of media and technology due to its vast use in everyday life. Children can rather be diverted from misuse to proper use where they can learn an additional language with fun and playing. Cartoons, movies, and other shows on TV/YouTube can play a cardinal role in language learning outside the language classroom and traditional system.

As most of the children, at present, mainly in urban areas, spend their leisure by watching TV cartoons or YouTube videos, or Facebook, they can utilize these platforms for so many purposes or as a medium of learning more than one language. Because, the content, language, pronunciation, and story of kids-shows are chosen considering children's choice and capability so that children can easily understand the contents and feel attraction. Odukomaiya (2014) said that cartoons make the learning process faster especially in the case of children than adults though these cartoons have some negative impact on children becoming violent. Children have a great eagerness to learn new things than grown-ups.

While watching cartoons or other TV shows which children prefer most, they enjoy a lot and pay close attention to those watched programs and try to inculcate the language used in cartoons or TV programs in their daily communication. As the language of these shows is lucid and easy to understand, they can master that language unconsciously. Needless to say, this 
spontaneous process of learning is the best method of learning not only language but also anything because they do not need to be laborious to learn. Moreover, they can learn the second language just passing their leisure with some playful mode if they want to do that.

\section{LITERATURE REVIEW}

Nowadays, a noticeable number of researchers are working on language learning. Media and cartoon channels are considered as ways of acquiring a new language and correcting the target language easily. Svetozar Poštić (2015) has shown that how the Lithuanian students acquire their expertise in American English accents like the native speakers just for watching Cartoon Network in their childhood. As to say, media can change a man's life and thinking patterns if the man is devoted to them while using. Changes are inevitable for children because they are very much imitative and they learn what they observe in their surroundings. When children get a character like them in a cartoon or any TV show, they start thinking of becoming that character and behaving and speaking like that character. This is because children learn through imitations and develop certain actions in real life by the things they watch in cartoons (Cohen, 2006). The tendency of imitation is not futile particularly for children who are going to school. They have a strong addiction to cartoons and this addiction has a great impact on the children's every day doing. They have an affinity to show their attitudes and actions like their dream characters shown in cartoons (Arshad \& Zafar, 2018). Children are like mud with which anyone can give a shape according to their wish. Children also try to copy behaviors and daily activities done by adults with them. Their moral and mental development as well as the ability to learn the language are influenced by the impact of cartoons though their parents always concern for aggressiveness presented in cartoons (Tripathi et al., 2016).

Jean-Marc Dewaele (2015) mentions the way of being multilingual that the single parent, single language method in which a native tongue is spoken by one parent and the other language is used by another parent with the children to achieve the target languages simultaneously. But parents of the modern speedy world cannot manage time for spending enough time with children. Parents are working days and nights home and outside to maintain their expenses of daily cost. As parents are busy with their deeds all day long, they need some rest after coming back home. In most cases, children are given some entertainment devices like mobile, television, tab, etc. for keeping them separate.

Generally, cartoons are used only for entertainment purposes; but they have some educative benefits also. In addition, cartoons help children become bilingual and get proficiency of languages specifically foreign languages (Lodhi, et al, 2018; Zitouni, et al.,2021). King \& Fogle (2006) stated that bilingualism can be developed at home by reading books, watching videos, and television programs. Besides these, CD and DVD of music also play a role in second language learning. Moreover, ELT students can enrich their incidental type of vocabulary just by watching cartoons with subtitles or (Karakas \& Sariçoban, 2012; Ferrati, 2021). Students enjoying cartoons/movies with captions are more efficient to handle any unknown situation than the students who don't watch cartoons or movies or other programs.

\subsection{Background of the Study}

After reviewing the literature, we notice most of the researchers have focused on the impact of the cartoons or media influence in language learning and either their negative or positive effects on children. But there is no clear comparative study between rural and urban children 
in the Bangladeshi social context to show the significance of how media and technology play a role in developing children to be bilingual and multilingual. There are a plethora of opportunities for children in the urban area whereas the children of the rural area have a scarcity of modern facilities.

Moreover, what children do in their leisure time and how the facilities of media and technology are in both urban and rural areas should be examined for getting full-fledged evidence of the influence of media and technology (cartoons, movies, video clips, and so many things) that are undoubtedly important for children's bilingualism and multilingualism. This comparative study aims at fulfilling the gap of the research regarding cartoons and media influence on language learning.

\subsection{Research Questions}

This study aims to find out the influence of media and technology like YouTube/Television on children to be bilingualism or multilingualism. Particularly, this study seeks answer to the following questions:

i. How many children from the rural and urban areas are bilingual and multilingual?

ii. Are media and technology (TV/YouTube programs) helpful for children becoming bilingual or multilingual?

iii. How much impact do TV shows/cartoons have on rural and urban children to be bilingual or multilingual?

\section{METHODOLOGY}

\subsection{Research method}

The quantitative research method was used in this investigation. Because the data were collected through a questionnaire and individual interview and the researcher had easy access to the data, this approach was deemed appropriate for the study.

\subsection{Sampling Technique}

For this study, stratified sampling technique was followed. Based on the sampling method, the researchers chose 2 thanas out of 9 thanas of Sirajgong district randomly and samples were selected from a larger population conveniently. Since the objective of the research is demonstrate the comparative result of the effect of media and technology on rural and urban children regarding second language learning, samples were divided into two categories, rural children and urban children.

\subsection{Participants of the Study}

As this study is to identify how media and technology influence children to learn second language, children of 8-10 years old who studied in different levels [from class 1 to class 10] were considered as the participants for this study. The sample size was 200 (100 from urban and 100 from rural). Bangla was the mother tongue of all participants.

\subsection{Data Collection Procedure}

Primary data were collected from rural and urban primary and secondary schools through a questionnaire and interview method. For collecting data, the researchers have visited 3 different private schools in primary and secondary level of Sirajganj town, Sirajgonj and 5 government primary schools from the villages of Enayetpur thana under Sirajganj district.

The researchers used close-ended questions (Appendix) and authenticity of participants' language(s) proficiency was also testified by asking them to communicate with others with using the new language(s) which they learned from YouTube/TV. What is more, whenever 
anyone failed to understand the questionnaire, researchers helped them solve the problem immediately. After collecting data, it had been counted manually with great caution so that the result would be accurate and data were recorded in tabular format.

\section{FINDINGS}

This section will provide results in tabular format and the results are shown in percentage.

Table 1: Number of speaking languages

\begin{tabular}{llll}
\hline & Number & Rural & Urban \\
\cline { 2 - 4 } Q. 'How many languages can you speak & 1 & $95 \%$ & $32 \%$ \\
in?' & 2 & $5 \%$ & $63 \%$ \\
& More than 2 & $0 \%$ & $5 \%$ \\
\hline
\end{tabular}

Table 1 shows that places and facilities have a noticeable impact on language learning. In a rural area, the majority percent $(95 \%)$ of the children are monolingual and a very limited number are bilingual. On the other hand, $63 \%$ of children are bilingual whereas $32 \%$ are monolingual.

Table 2: Spending leisure time

\begin{tabular}{llll}
\hline & Contents & Rural & Urban \\
\cline { 2 - 4 } $\begin{array}{l}\text { Q. How do you } \\
\text { spend your leisure }\end{array}$ & $\begin{array}{l}\text { Playing outdoor game } \\
\text { computer/mobile }\end{array}$ & $63 \%$ & $20 \%$ \\
time? & $\begin{array}{l}\text { Watching TV/YouTube } \\
\text { Traveling with family }\end{array}$ & $32 \%$ & $13 \%$ \\
& & $02 \%$ & $52 \%$ \\
\hline
\end{tabular}

In Table 2, it has been noticed that $63 \%$ of rural children spend their leisure playing outdoor games while $30 \%$ of urban children spend their leisure playing outdoor games which is half of the rural children. The percentage of watching TV/YouTube in the urban area is 52 whereas $32 \%$ is in the rural area.

Table 3: Name of languages children can speak

\begin{tabular}{llll}
\hline & Contents & Rural & Urban \\
\cline { 2 - 4 } Q. Which language(es) can you speak in? Bangla & $95 \%$ & $24 \%$ \\
& Bangla \& English & $4 \%$ & $15 \%$ \\
& Bangla \& Hindi & $1 \%$ & $61 \%$ \\
& Urdu & 0 & 0 \\
\hline
\end{tabular}

In Table 3, most of the students who enjoy TV/YouTube programs like Hindi cartoon can speak in Hindi fluently. 95\% of children in a rural area can speak only one language (Bangla) because they don't watch cartoons or movies etc. as urban children do. The scenario of urban is noticeably different. $61 \%$ of children in urban can speak in Hindi along with Bangla whereas only $1 \%$ from rural speak Hindi programs.

Table: 4: Watching time of television

\begin{tabular}{llll}
\hline & Time & Rural & Urban \\
\cline { 2 - 4 } Q. How much time a day do you spend & $1-2$ hours & $83 \%$ & $90 \%$ \\
watching TV? & 3-4 hours & $15 \%$ & $9 \%$ \\
& 5-6 hours & 02 & 01 \\
\hline
\end{tabular}

In Table 3, when children are involved in fun activities, they don't feel any fatigue and boredom. They can learn new things with entertainment and new ways. It is surprisingly 
noticeable that children who are selected don't waste more time watching Television. 83\% of children from rural and 90\% from urban spend only 1- 2 hours watching television in a day.

A significant number of respondents from rural and Urban spends 1- 2 hours watching TV ( $83 \%$ and $90 \%$ respectively) while 3-4 hours are used by a very limited percentage (15\% rural and only $9 \%$ urban) of Children.

\section{Table: 5: Preferable programs of Children}

Q. What type of program do you prefer to watch?

\begin{tabular}{lll} 
Contents & Rural & Urban \\
\hline Cartoon & $63 \%$ & $72 \%$ \\
Movie & $22 \%$ & $24 \%$ \\
Serial & $10 \%$ & $03 \%$ \\
Reality show & $05 \%$ & $01 \%$ \\
\hline
\end{tabular}

From table 5, the result shows that most of the children prefer cartoons $(63 \%$ in rural; $72 \%$ in urban). Other programs like movies, serials, reality shows are also enjoyed in certain percentages.

Table: 6: Language of preferable programs

\begin{tabular}{llll}
\hline & Contents & Rural & Urban \\
\cline { 2 - 4 } Q. Program of which language do you & Only Bangla & $68 \%$ & $19 \%$ \\
enjoy more? & Bangla \& English & $05 \%$ & $11 \%$ \\
& Bangla \& Hindi & $17 \%$ & $70 \%$ \\
& Others & $0 \%$ & $0 \%$ \\
\hline
\end{tabular}

It is surprisingly noticed that those who prefer cartoons or movies or others programs in Bangla \& Hindi language are more bilingual/multilingual. A significant result is found in an urban area where $63 \%$ of children are bilingual who can speak in Hindi along with their mother tongue (Bangla) and 5\% of children are multilingual [Table:1]. Table 6 shows that programs of Bangla and Hindi language are highly preferable to urban children (70\%).

Table: 7: Using learned language from media in real life

\begin{tabular}{llll}
\hline Q. Do you use the language that you learn from & Impression & Rural & Urban \\
\cline { 2 - 4 } $\begin{array}{l}\text { different programs in real life? } \\
\text { Yes }\end{array}$ & No & $67 \%$ & $66.73 \%$ \\
\hline
\end{tabular}

Table 7 shows that children of urban practice the language learned from media more than those of rural. $66.73 \%$ and $33 \%$ of children of urban and rural respectively replies to the question yes. $67 \%$ of rural children and $33.27 \%$ of urban children cannot use the language that they learn from different YouTube/TV programs.

Table: 8- Modern facilities

\begin{tabular}{llll}
\hline & Impression & Rural & Urban \\
\cline { 2 - 4 } Q. Do you have Wi-Fi at your home? & Yes & $05 \%$ & $69 \%$ \\
& No & $95 \%$ & $31 \%$ \\
\hline
\end{tabular}

In table 8 , most of the families of urban (69\%) have Wi-Fi facilities where a very limited percentage (only $5 \%$ ) is in rural.

\section{DISCUSSION}

It is very common today parents pass their time so hasty that they cannot give much time for feeding their children. As to why they use mobile phones or televisions so that children can 
have their meal with a possible short time. Besides, Parents and other family members also remain busy with modern technology while staying home without passing time together by playing or gossiping. In this way, children become addicted to mobile, television, and other modern technology. The research shows a 52\% [Table: 2] of urban children pass their leisure just watching television. It has some linguistic gains for the children. In this research, the focus groups bring a significant result that supports the influence of media and technology on language learning among rural and urban children. As rural children spend less time watching television or using mobile phones than urban children, the number of bilingual and multilingual children of urban is higher than that of rural. Table 3 shows that $61 \%$ and $15 \%$ of urban children can speak Hindi and English along with Bangla respectively where the percentage of rural children is very low (only 1\% Bangla \& Hindi and 4\% Bangla and English).

As some children are multilingual, they can communicate in Hindi and English besides Bangla. The researchers wanted to know how why they achieve these languages and ask them "Do you use the language that you learn from different programs in real life?" Urban Children who are bilingual reply "Yes" (66.73\%) [Table: 7] also say that they practice dialogue learned from cartoons or movies with their friends for fun and automatically with the time being, they have mastered over the languages. The scenario is not the same in the rural area. The facilities of modern technology in the pastoral area are not sufficient though some rural children have some chances to pass their time by watching cartoons in different languages. Some of them can speak in Hindi and among them, 33\% practice the language that they enjoy on television/YouTube, and $67 \%$ answered negatively [Table: 7].

At present, it is noticed that parents have also become serious about bilingualism and multilingualism. They want their children to be bilingual and multilingual for their bright future. Because parents believe that knowing more than one language enhances the soft skills of the children and the opportunity of getting jobs must be higher. Besides, they may earn a six-figure income as well as be benefitted in developing their career, building advanced communication, achieving individuality for bilingualism (Lee et al., 2015).

To fulfill parents' desire for making their children bilingual/multilingual, cartoon and other programs for children can be an effective platform for language learning. It is conspicuous that children who have more access to media and technology perform better in language learning than those who are devoid of these facilities. This study finds that the number of bilingual and multilingual is $63 \%$ and $5 \%$ in urban while this percentage in rural is tremendously low (5\% and 0\% respectively) [Table:8] due to lack of modern facilities like internet/Wi-Fi which is the key tools for allowing children to meet with various programs from different languages. This unavailability of modern technology pushes the rural children's leg behind and they may not be able to compete with the upcoming challenges like competition in job markets, adaption ability with the fast-growing world, etc. of the $21^{\text {st }}$ century. As Smith (2017) says, if you know a language, it will take you in the corridor of life. But when you know more than one, it will open every door of knowledge before you.

Bilingualism and multilingualism will create a great number of opportunities for children to learn various cultures, customs, countries, etc., and children will be able to cope with the modern world. To meet the demand of the present world, several language institutions are established to teach different languages to students all over the world. It needs a large amount of cost and time to learn a new language. Moreover, it is very difficult and tedious to be a skilled user of the target language for all classes of people. Besides, boring, time- 
consuming, and costly processes demotivate learners to be bilingual and multilingual. If children learn from what is happening around them, it would be more fun for them. As G. Ozbal and C. Strapparava (2011) proposed an automatic model, Moving Effective Assonance for Novice Students (MEANS) which helps learners of the second language (L2) to memorize new words with involving sentences, colors, animations, and images, together with the translation and pronunciation of the target language for memorizing vocabulary automatically (Ozbal \& Strapparava, 2011).

The result of the study shows that by learning words and pronunciations of languages from cartoons or TV shows, children can use them in their daily communication and learn gradually the target language(s) up to their competent level [Table:7]. According to My (2021), undertaking video-based projects made grammar courses more authentic.

Another thing that has a noticeable impact on language(s) learning is the amount of time spent by children in front of the television for watching cartoons/ favorite programs. Those who spend more time with televisions result in a good number of bilingual and multilingual. Though a great number of percentages from rural and urban spend 1-2 hours in front of the television, there is a variation in language choice for programs. Children of rural (68\%) prefer Bangla cartoons when urban children (70\%) choose both Bangla and Hindi and in some cases $11 \%$ of children like English with Bangla [Table: 6]. So, the result in the rural and urban areas is not the same. A significant difference has been found regarding learning language(s) from media (TV/YouTube programs) due to the unavailability of Wi-fi and TV facilities as well as plenty of opportunities for spending time without using modern technology. If we ensure the modern amenities among the rural and urban children, the result must be different. Taking the above information into consideration, it can be, undoubtedly, said that there is a significant influence of media and technology on children to be bilingual and multilingual.

\section{RECOMMENDATION}

The following recommendation is presented here.

i. Media and technology (TV/YouTube/mobile phones) can be used as a language learning tool.

ii. More language-based programs especially cartoons should be made for children.

iii. Programs should be censored by parents before allowing children to watch.

iv. Parents should select the target language to make their children bilingual/multilingual.

v. Selected programs must be based on the intended language.

vi. Watching time should be fixed for children to prevent them from addiction to media.

vii. Overall, parents should think of children's health care issues.

\section{PROBLEM STATEMENT}

Primary data collection is time-consuming and costly. It is hard to reach all corners of the country to collect accurate information. Moreover, children and parents are not familiar with the research process that is why they unable to provide sufficient information according to the questionnaire. 


\section{CONCLUSION}

To recapitulate, the usage of media and technology (TV/YouTube programs) has a great positive impact on children in the case of bilingual/multilingual users though the percentage varies from city to the pastoral area. As we cannot keep our children outside the network of technology, we can divert the technologies from misuse to proper use so that our children can learn languages with fun and play. Cartoons, movies, and other programs on TV/YouTube play a great role in language learning outside the language classroom and traditional system. Our children will learn a language(s) with a language-based program which is a highly effective way of language learning. Parents should shun up the existing bad idea of the usage of technologies for children. To take the rural children in the same line as urban children, we have to ensure proper advanced facilities like wi-fi, Television, etc. in the villages. It would be great to use the media and technology effectively for ensuring the facilities of learning language(s) for everyone especially children who, getting the benefits of media and technology will be bilingual and multilingual without having any institutional training.

Future research

More research may be conducted on the influence of modern technology like Television, YouTube, Netflix, Facebook videos/cartoons etc. on children's accent and pronunciation of different languages.

\section{REFERENCES}

Arshad, M., \& Zafar, N. (2018). Cartoon Addiction and Executive Functioning in School Going Children. Global Journal of Addiction \& Rehabilitation Medicine, 5(4), 68-75.

Cohen, J. (2006). Audience identification with media characters. Psychology of entertainment, 13, 183-197.

Dewaele, J.-M. (2015). Bilingualism and Multilingualism. In The International Encyclopedia of Language and Social Interaction1-11. (eds K. Tracy, T. Sandel and C. Ilie). https://doi.org/10.1002/9781118611463.wbielsi108

Ferrati, A. (2021). Global Media and Cultural Identity: Opportunities and challenges for Morocco in the Digital Era. International Journal of Language and Literary Studies, 3(3), 109-120. https://doi.org/10.36892/ijlls.v2i3.673

Karakas, A., \& Sariçoban, A. (2012). The Impact of Watching Subtitled Animated Cartoons on Incidental Vocabulary Learning of ELT Students. Teaching English with Technology, 12(4), 3-15.

King, K., \& Fogle, L. (2006). Raising bilingual children: Common parental concerns and current research. CALdigest Series, 2, 2-3.

Lee, M., Shetgiri, R., Barina, A., Tillitski, J., \& Flores, G. (2015). Raising bilingual children. Hispanic Journal of Behavioral Sciences, 37(4), 503-521. https://doi.org/10.1177/0739986315602669

Lodhi, M. A., Ibrar, S. N., Shamim, M., \& Naz, S. (2018). Linguistic Analysis of Selected TV Cartoons and Its Impact on Language Learning. International Journal of English Linguistics, 8(5), 247.

My, N. V. (2021). Positive Effects of Video-based Projects on the Communicative English Grammar Lessons. International Journal of Language and Literary Studies, 3(3). https://doi.org/10.36892/ijlls.v3i3.666 
Odukomaiya, E. I. (2014). Cartoons influence towards violence and aggression in school age children in Nigeria (Doctoral dissertation, Eastern Mediterranean University (EMU)Doğu Akdeniz Üniversitesi (DÄ̈)).

Ozbal, G., \& Strapparava, C. (2011). Automatising language creativity for learning second language vocabulary. International Journal of Continuing Engineering Education and Life Long Learning, 21(2-3), 222-234.

Poštić, S. (2015). Influence of Cartoon Network on the Acquisition of American English During Childhood. Institute of Foreign Languages, pp.188-195

Smith, F. (2017). To think: In language, learning and education. Routledge.

Tripathi, P., \& Singh, A. (2016). The Effect Of Cartoon On Children. Asian Journal Of Home Science, 11(2), 400-403. https://doi.org/10.15740/has/ajhs/11.2/400-403

Zitouni, M., Al-Traif, H., Zemni, B., Mohammed, O. S., \& Aljasser, M. (2021). Utilization of YouTube to improve the pronunciation skill of Saudi learners in translation departments. Asian ESP Journal, 17(2), 133-154.

\section{AUTHORS'BIO}

Md. Sozib Hosen, a university lecturer, has been teaching English Language and Literature for more than 4 years. He is also a researcher in second language acquisition and linguistic studies. His current research interests include second language learning methodology, influence of media and technology on language learning and acquisition, ESL, TESOL, Sociolinguistics, testing of ESL grammar and spelling, applied linguistics. Some articles of this researcher have already been published in renowned national and internal journals. He completed his BA (Hons) in English and Master in English from Islamic University, Kushtia, Bangladesh.

Mst. Tanna Khatun works as a lecturer in Khwjaja Yunsus Ali University for more than 4 years. She teaches linguistics, SLA and Psycholinguistics, syllabus and material design, English language: advance writing skills, English for professional purposes. Her research area includes SLA, TESOL, linguistics, testing and evaluation of ESL. She did her BA (Hons) in English and master in English from Islamic University, Kushtia, Bangladesh. 